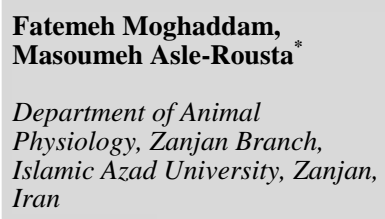

*Corresponding Author: Department of Animal Physiology, Zanjan Branch, Islamic Aza University, Zanjan, Iran

Tel: 0912- 5606327

E-mail: mrousta@iauz.ac.ir

\section{Effect of Summer Savory (Satureja Hortensis L.) on the Concentration of Gonadotropins and Testosterone in Male Rats Exposed to Chronic Immobilization Stress}

\author{
Received:16 Oct. 2016 ; Accepted: 10 Feb. 2017
}

Background: Summer savory- Satureja hortensis L. is from Lamiaceae family and has antioxidant, anti-inflammatory, anti-apoptotic properties. The purpose of this study is to investigate the effect of hydro-alcoholic extract of Summer Savory leaves on the level of LH, FSH and testosterone in male rats exposed to chronic immobilization stress.

Material and Methods: This study was conducted experimentally. 48 adult male Wistar rats were divided into 6 groups including: Control, Stress, Savory 200, Savory 400, Stress-Savory 200, and Stress-Savory 400. Groups 2, 5, and 6 were placed into restrainer for 6hours per day during 21 consecutive days and groups 3, 4, 5, and 6 were gavaged by hydro-alcoholic extract of Summer Savory with different doses of $200,400 \mathrm{mg} / \mathrm{kg}$ during 21 consecutive days. The level of LH, FSH and testosterone were measured by the end of period.

Results: Chronic Immobilization caused significant decrease in serum concentrations of LH $(p<0.01)$, FSH $(p<0.01)$, and testosterone $(p<0.001)$ in stress group compared with the control group and taking both doses of plant extracts inhibited the above effect.

Conclusion: It is concluded that the Satureja hortensis extract may stimulates the hypothalamic-pituitary-gonadal axis and prevents stress-induced reproductive damages.

Keywords: Summer savory (Satureja hortensis L.), immobilization stress, LH, FSH, testosterone. 
تأثير عصاره هيدروالكلى مرزه تابستانى (Satureja hortensis L.) بر غلظت

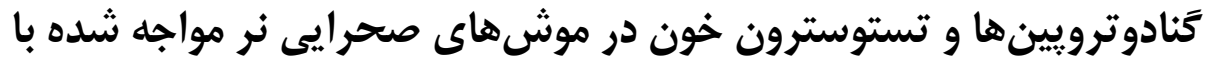

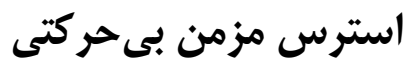

فاطمه مقدم'، معصومه اصل روستا "s"

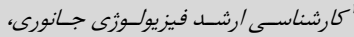

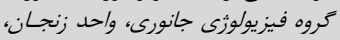

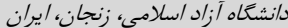

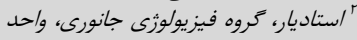

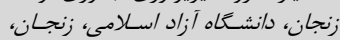
ايران

تاريخ دريافت مقاله: 9ه/V/Tه ؛ تاريخ پذيرش: I

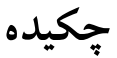

زمينه: مرزه تابستانى (L Satureja hortensis.) از خـانواده Lamiaceae و داراى اثـرات آنتسى اكسـيدانى، ضـادلتهابى و

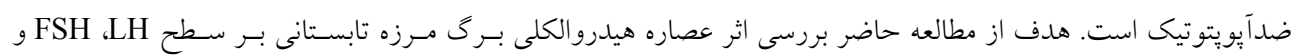

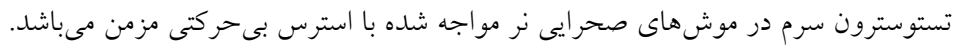

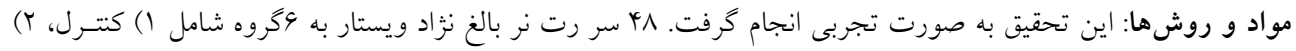

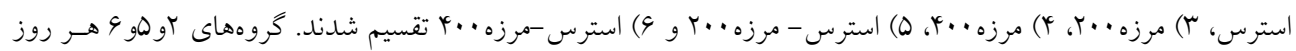

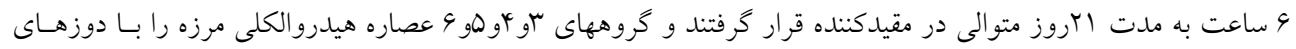

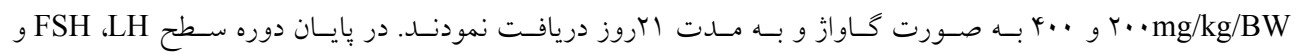

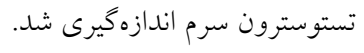

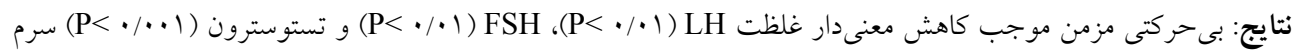

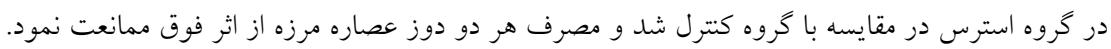

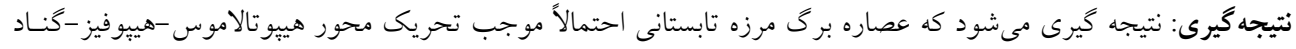

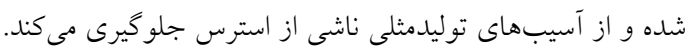
كلمات كليدى: مرزه تابستانى(L Satureja hortensis.)، استرس بيحركتى، LH، FSH، تستوسترون

نو نو فيسنده مسئول: كروه فيزيولوزى جانورى، واحد زنجان.

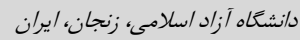

$.91 \%-\Delta 9.9 T T Y$

E-mail: mrousta@iauz.ac.ir 


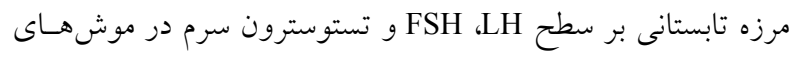

صحرايى نر بالغ تحت استرس مزمن بيحركتى مـورد مطالعهـ قـرار كرفته است.

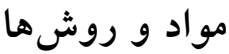

رتهاى نر بالغ نزاد ويستار در محدوده وزنى •بr-..بكرم از

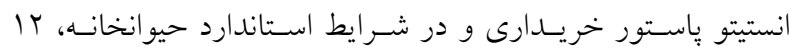

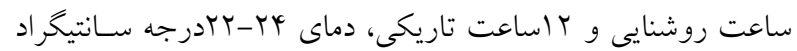

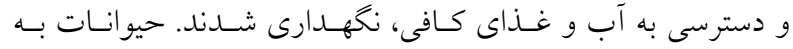
صورت تصادفى به وكروه (هر خـروه شـامل ^ مسر مـوش) تقسيم

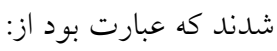
ا- كروه كترل: موشهايى كه تحت استرس بيحر كتى و تجويز عصاره قرار نخرفتند. ץ- گروه استرس: موشهايى كه تحت استرس مـزمن بيحركتى

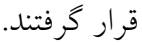

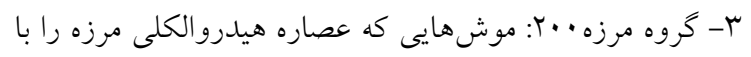

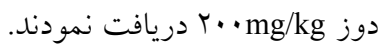

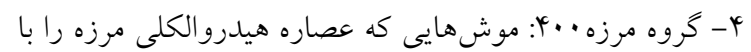
دوز ه- گروه استرس - مرزه ..厂: موشهايى كه علاوه بـر استرس،

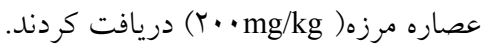

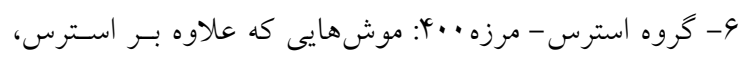
عصاره مرزه ( حيوانات گروههاى استرس، به مدت الب روز متوالى هر روز بـهـ

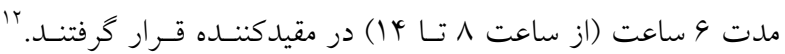

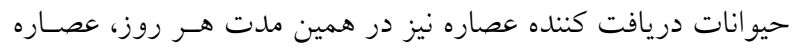
هيدروالكلى مرزه را به صورت كاواز دريافت كردند.

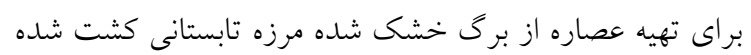
در مزارع خدابنده استفاده شد. كياه توسط كروه كياهشناسى مركـز تحقيقات بيولوزيكى دانشكاه آزاد اسلامى واحد زنجـان مـورد تأييـد

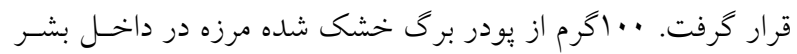

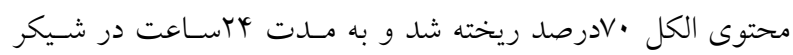

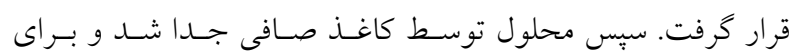

در سيستمهاى بيولوزيك، استرس به حالتى كفتـه مسىسود كـه

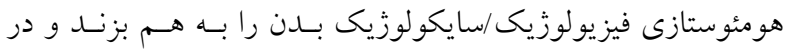
حوزه نورواندوكرين به معنسى باسـخهاى هورمهونى بـهـ تقاضـاهاى

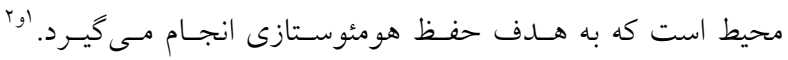

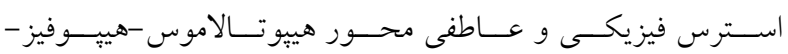

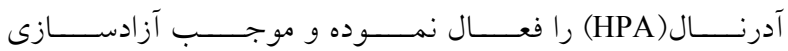

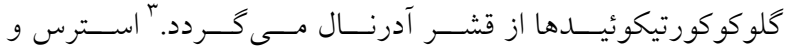
كلوكو كورتيكوئيدها به صورت مركزى و محيطى موجب مهار محور

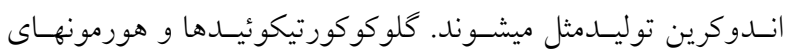

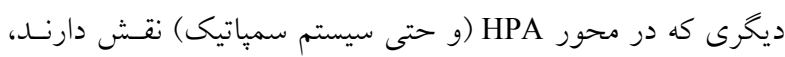
عملكرد محور هييو تالاموس -هييوفيز -كناد (HPG) را تنظيم مى كنند. كلو كو كورتيكوئيدها ميتواند موجب مهار ترشح هورمسون آزادكنتـده

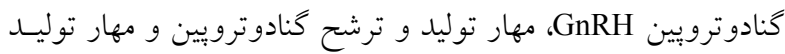
و ترشح تستوسترون از بيضه شوند و بر كامتوزنز و رفتار جنسى نيز تأثير مى كذارند. يكسى از نتـايج افـزايش غلظـت كلوكوكورتيكوئيسـدها در بـــن،

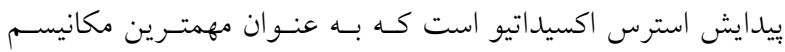
ياتولوزيك در سازش نامناسـب در برابـر اسـترس مـزمن بيحركتى

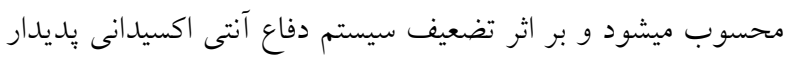

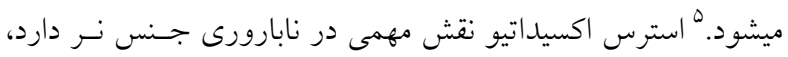

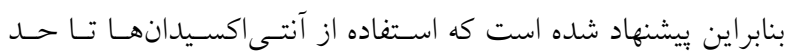
زيادى مسى توانـــ عواقـب ناشسى از اسـترس اكسـيداتيو بــر سيستم توليدمثلى را كاهش دهد. كاهان ك. ن Satureja hortensis كياهان كونه Satureja است كه به خـانواده Lamiaceae (نعناعيـان) تعلق دارد. مرزه حاوى مواد شيميايى مختلف فعال مانند روغن هاى فرار، تركيبات فنلى، فلاونوئيدها، تانن، استروئيدها، اسيدها، موسيلاز

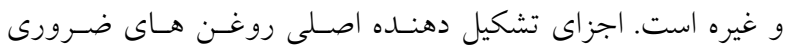
عبارتند از:كارواكرول، تيمول، فنل و فلاونوئيدها.

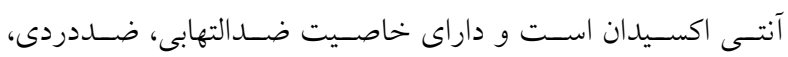

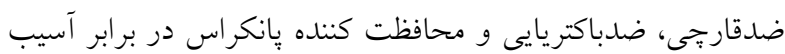

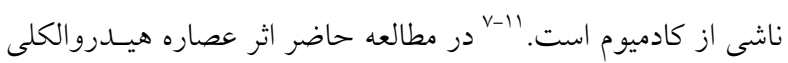




$$
\text { اندازه كيرى گرديد. }
$$

مطالعات آمارى با استفاده از نرم افزار SPSS v18 انجام كرفـت.

نتايج حاصل به صورت ميانخين \pm انحراف معيـار ارائسه شـــ. بــراى

تجزيه و تحليـل اطلاعـات از One-way ANOVA و Tukey HSD post hoc استفاده شد. ه• P> به عنوان سطح معنسى دارى نتـايج در نظر كرفته شد.
حذف حلال در روتـارى تحـت دمـاى •ه درجـه سـانتيخراد قـرار كرفت. در نهايت با افزودن آب مقطر، دوزهاى مـورد نظـر عصـاره تهيه شد. حجم عصاره دريـافتى توسطط هـر حيـوان در هـر كـاواز، . بودا

در بايان دوره، حيوانات توسط كلروفرم بيهوش شــناند و خــون ب...rpm به طور مستقيم از قلب كرفته شد، سرم توسط سانتريفوز جدا و سطح هورمونهاى FSH و FH و تستوسترون بـهـ روش الايـزا
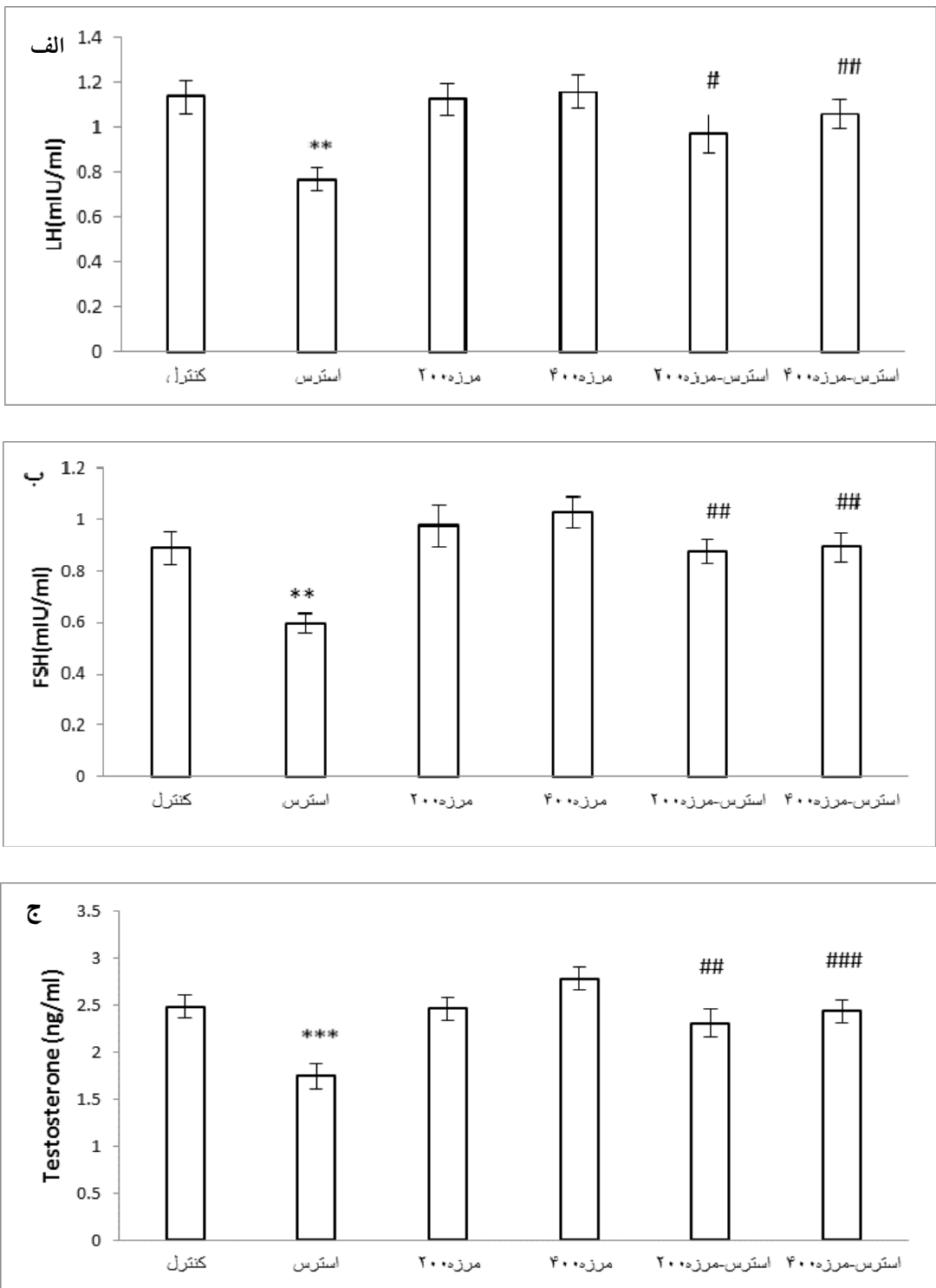

شكل (. تأثير عصاره مرزه بر سطح الف) LH و ج) تستوسترون سرم در موشهاى صحرايى تحت استرس مزمن بى حركتى. نتايج به صورت ميانكين

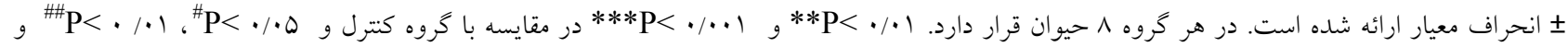

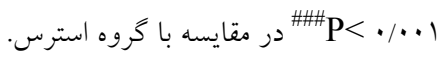


موجب كاهش ترشح تستوسترون مى گردد. ال استرس بيحركتى مزمن موجب آتروفى لولههاى سمينيفر و كاهش تعداد اسبرم مىشود، امـا تـأثيرى بـر سـطح بيـان يــروتئين Steroidogenic acute ) StAR

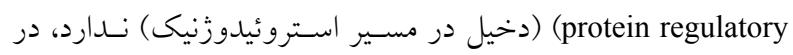
حالى كه بيان بروتئين مذكور در سلولهاى ليديخ در استرس حساد بيحركتى كاهش مى يابد كه بيانخر كاهش استروئيدوزنز است. ^اوث|

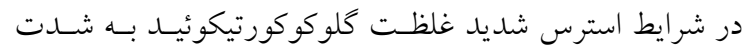
افزايش مى يابد. مقادير فراوان اين هورمونها موجب القـاى آيويتسوز

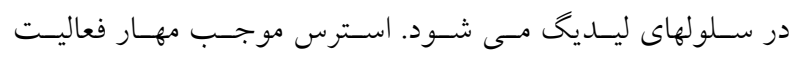

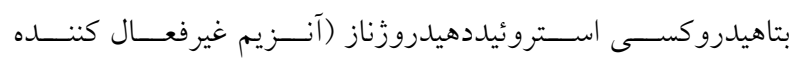

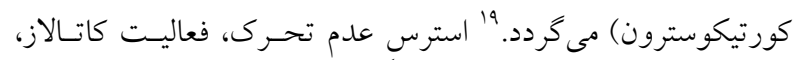
كلوتاتيون بركسيداز، كلوتاتيون ترنسفراز و گلوتاتيون ردوكتاز رادر بافـت بينـابينى بيضـه كـاهش مسىدهــــ و بـــين ترتيـب، سيسـتم

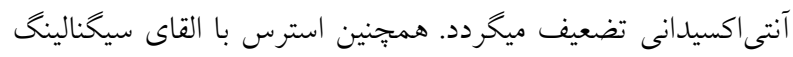

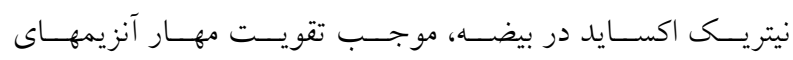

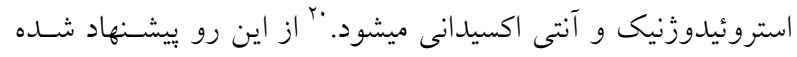
است كه بكارگيرى آنتىاكسيدانها موجب كاهش استرس اكسيداتيو

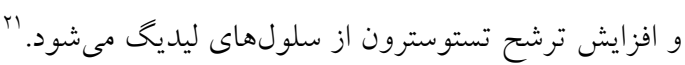

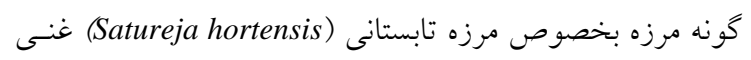

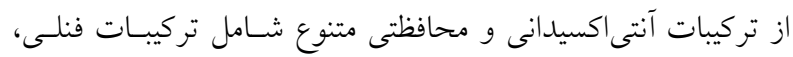

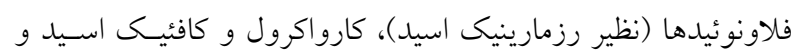

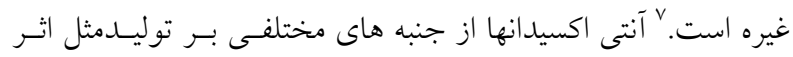

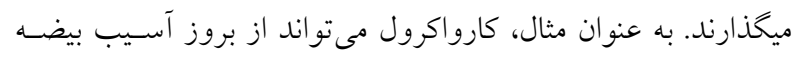
ناشى از متوتركسات ممانعت كند. تيمار درون صفاقى كارواكرول از بروز استرس اكسـيداتيو و افـزايش مـالون دالدهيـد و اكسـيدانها در خون و بيضه موش هاى تحت تيمار متوتركسات ممانعـت نمـودهه و سطح آنتى اكسيدانها را افزايش مىدهد. بَ فلاونوئيدها نيـز موجـبـ

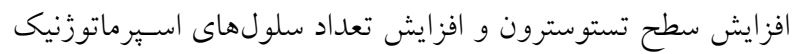
در موش هاى مدل ديابت القا شده توسط الوكسان مىشوند. بَّتيمار

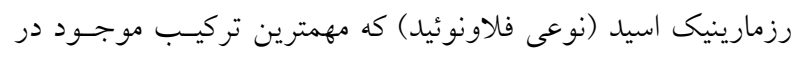

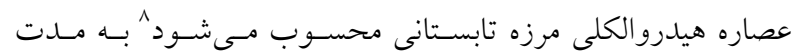

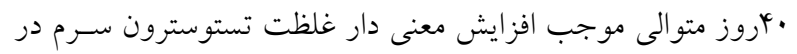
موش هاى صحر ايى مى گردد اما اثرى بر غلظت LH و FSH ندارد.
غلظت هورمسونهـاى LH و FSH درخــروه اسـترس در مقايسـه بـاــا كنترل، به طرز معنى دارى كمتر بـود ( ( P > P) و همجنـسين سـطح

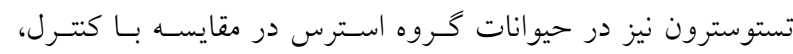

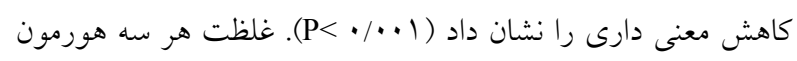

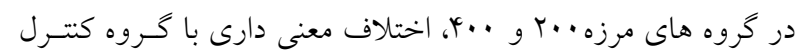

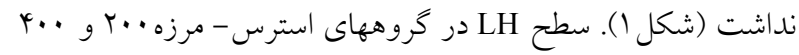
افزايش معنى دارى در مقايسه با گـروه اسـترس داشـت (بـه ترتيـبـ

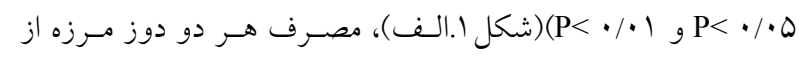
كاهش غلظت FSH در مـوشهــاى تحــت اسـترس ممانعـت نمـود

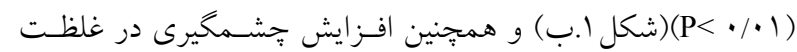

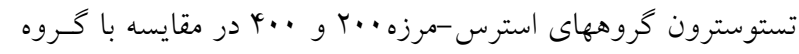

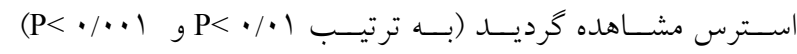

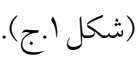

\section{بحث و نتيجه گيرى}

نتايج حاصل از مطالعه حاضر نشان داد كه استرس بسى حركتى به مدت الرروز موجـب كـاهش غلظـت LHH FSH و تستوسـترون

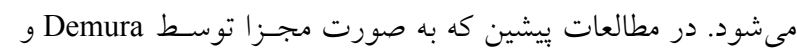

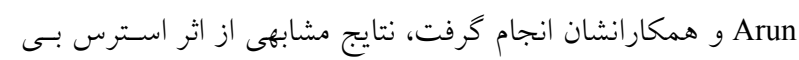

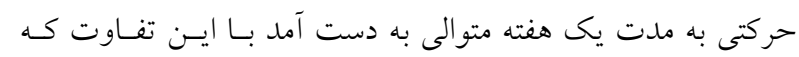

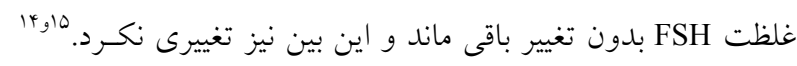
شايد اين اختلاف به علت طول مدت القاى استرس در حيوان است كه با افزايش دوره به ابروز، ترشح FSH را نيـز تحست تـأثير قـرار

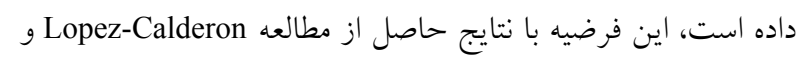

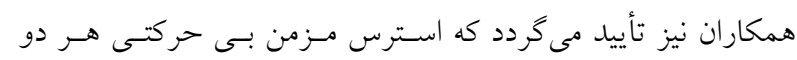

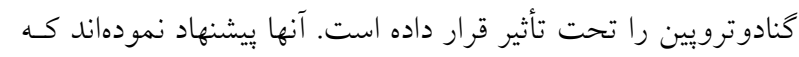
كـاهش غلظـت LH ناشسى از كـاهش ترشـح LHRH اسـت و و بــه باسخدهى هيبوفيز بيشين به هورمون مـذكور ارتبـاطى نــارد.

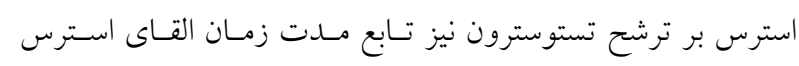

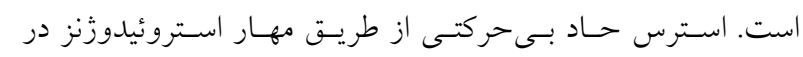
سلولهاى ليديخ بر غلظت تستوسترون اثر مى خذارد در حسالى كـهـ استرس مزمن از طريق تأثير بر محور هيبوتالاموس-هيبيوفيز -بيضسه، 
ناشى از سيكلوفسفاميد را در موشهاى صحرايى كاهش مىدهـد و از كاهش سطح تستوسترون در اين حيوانات ممانعت مسى كنــ. ايسن

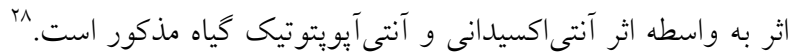
هم:جنين تيمار طولانى مدت عصاره هيدرو الكلى مـرزه تابسـتانى از كـاهش اسـبرمى ناشسى از آنتسى بيوتيـى ضدسـرطان doxorubicin

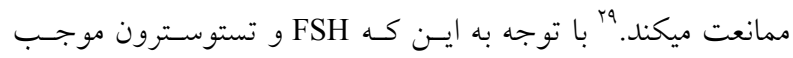

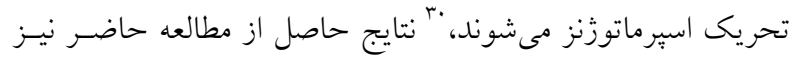
كه عصاره هيدروالكلى مرزه تابستانى از كاهش سـطح LSH LSH و تستوسترون ناشى از استرس مزمن بى حركتى ممانعت نمود، تأييدى بر مطالعات ييشين محسوب مىشود.

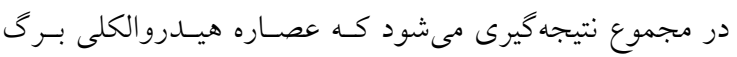

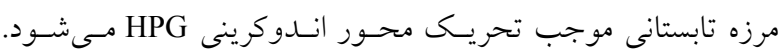

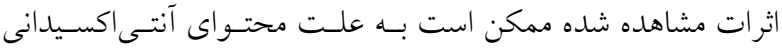

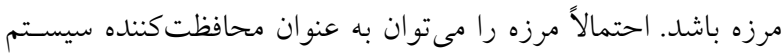
توليدمثل در برابر آسيبهاى محيطى در نظر كرفت.

\section{References}

1. Goldstein DS, McEwen B. Allostasis, homeostats, and the nature of stress. Stress 2002;5(1):8-55.

2. Selye H. Stress in health and disease. ButterworthHeinemann; 2013.

3. Franco AJ, Chen C, Scullen T, Zsombok A, Salahudeen AA, Di S, Herman JP, Tasker JG. Sensitization of the hypothalamic-pituitary-adrenal axis in a male rat chronic stress model. Endocrinology 2016;157: 2346-55.

4. Geraghty AC, Kaufer D. Glucocorticoid regulation of reproduction. Adv Exp Med Biol 2015; 872: 253-78

5. Zafir A, Banu N. Modulation of in vivo oxidative status by exogenous corticosterone and restraint stress in rats. Stress 2009; 12(2): 167-77.

6. Agarwal A, Makker K, Sharma R. Review article: clinical relevance of oxidative stress in male factor infertility: an update. Am J Reprod Immunol 2008; 59(1): 2-11.

7. Momtaz S, Abdollahi M. An update on pharmacology of Satureja species; from antioxidant, antimicrobial, anti diabetes and anti-hyperlipidemic to reproductive stimulation. IJP 2010; 6(4): 346-53. [In Persian]

8. Chkhikvishvili I, Sanikidze T, Gogia N, et al. Rosmarinic acid-rich extracts of summer savory (Satureja hortensis L.) protect jurkat $\mathrm{T}$ cells against oxidative stress. Oxid

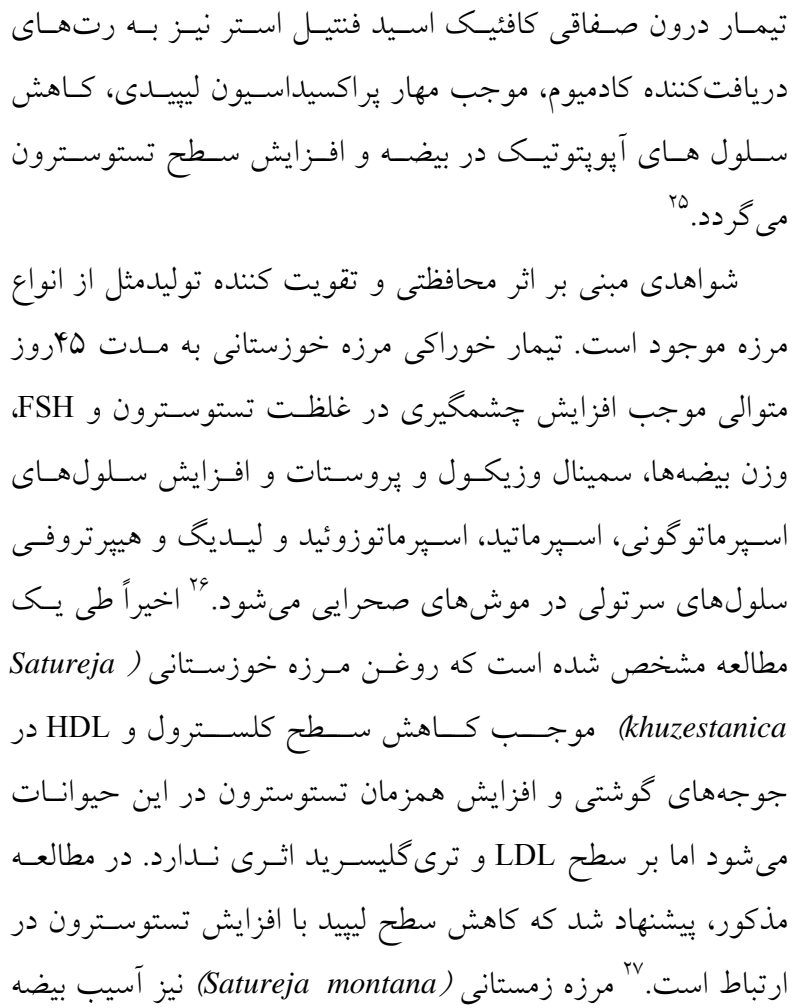

Med Cell longev 2013;2013.

9. Hajhashemi V, Ghannadi A, Pezeshkian SK. Antinociceptive and anti-inflammatory effects of Satureja hortensis L. extracts and essential oil. J Ethnopharmacol. 2002; 82(2): 83-7.

10. Güllüce $M$, Sökmen M, Daferera D, et al. In vitro antibacterial, antifungal, and antioxidant activities of the essential oil and methanol extracts of herbal parts and callus cultures of Satureja hortensis L. J Agric Food Chem 2003; 51(14): 3958-65.

11. Khorasgani EM, Haghdoost IS, Sedaghat R, et al. Satureja hortensis L.alcoholic extract ameliorates cadmium-induced pancreatic damage in rats. Middle-East J Sci Res 2013; 15(1): 32-5.

12. MacDowell KS, Caso JR, Martín-Hernández D, et al. Paliperidone prevents brain Toll-like receptor 4 pathway activation and neuroinflammation in rat models of acute and chronic restraint stress. Int J Neuropsychopharmacol 2015; 18(3): pyu070.

13. Mobarakeh HI, Dehkordi HS, Dehkordi MJ, et al. Assessing the Effect of the Savory (Satureja Hortensis L.) Essence on Some Biochemical Factors in Rat's Blood Serum. Adv Life Sci 2014; 4(2): 73-8. 
14. Arun S, Burawat J, Sukhorum W, et al. Changes of testicular phosphorylated proteins in response to restraint stress in male rats. J Zhejiang Univ Sci B 2016; 17(1): 21.

15. Demura R, Suzuki T, Nakamura S, et al. Effect of immobilization stress on testosterone and inhibin in male rats. J Androl 1989; 10(3): 210-3.

16. Lopez-Calderon A, Ariznavarreta C, Gonzalez-Quijano MI, et al. Stress induced changes in testis function. J Steroid Biochem Mol Boil 1991; 40(1): 473-9.

17. Marić D, Kostić T, Kovačević R. Effects of acute and chronic immobilization stress on rat Leydig cell steroidogenesis. J Steroid Biochem Mol Boil 1996; 58(3): 351-5.

18. Lin H, Yuan KM, Zhou HY, et al. Time-course changes of steroidogenic gene expression and steroidogenesis of rat Leydig cells after acute immobilization stress. Int $\mathrm{J}$ Mol Sci 2014; 15(11): 21028-44.

19. Hardy MP, Gao HB, Dong Q, et al. Stress hormone and male reproductive function. Cell tissue Res 2005; 322(1): 147-53.

20. Kostic TS, Andric SA, Maric D, et al. Inhibitory effects of stress-activated nitric oxide on antioxidant enzymes and testicular steroidogenesis. J Steroid Biochem Mol Biol 2000; 75(4): 299-306.

21. Glade MJ, Smith K. Oxidative stress, nutritional antioxidants, and testosterone secretion in men. Ann Nutr Disord \& Ther. 2015; 2(1): 1019.

22. Daggulli M, Dede O, Utangac MM, et al. Protective effects of carvacrol against methotrexate-induced testicular toxicity in rats. Int J Clin Exp Med. 2014; 7(12): 5511-6.
23. Shi J, Gong Y, Xie GY, et al. Protective effect of total flavonoids of herba epimedii on testis degeneration in diabetic mice. Zhongguo ying yong sheng li xue za zhi= Zhongguo yingyong shenglixue zazhi 2013; 29(5): 42831 .

24. Khaki A, Imani SA, Golzar FS. Effects of rosmarinic acid on male sex hormones (testosterone-FSH-LH) and testis tissue apoptosis after exposure to electromagnetic field (EMF) in rats. Afr J Pharm Pharmacol 2012; 6(4): 24852.

25. Erboga M, Kanter M, Aktas C, et al. Anti-apoptotic and anti-oxidant effects of caffeic acid phenethyl ester on cadmium-induced testicular toxicity in rats. Biol trace Elem Res 2016; 171(1): 176-84.

26. Haeri S, Minaie B, Amin G, et al. Effect of Satureja khuzestanica essential oil on male rat fertility. Fitoterapia 2006; 77(7): 495-9.

27. Khosravinia H. Hypolipidemic effects of Satureja khuzistanica essential oil in broiler chicken are realized through alteration in steroid hormones. Kafkas Univ Vet Fak Derg 2015; 21: 203-9.

28. El Tawab AM, Shahin NN, AbdelMohsen MM. Protective effect of Satureja montana extract on cyclophosphamide-induced testicular injury in rats. Chem Biol Interact 2014; 224: 196-205.

29. Shalizar Jalali A, Najafi G, Rahimzadeh P. Summer savory (Satureja hortensis) can reduce spermatotoxic effects of Doxorubicin in rats. Caspian J Reprod Med 2015; 1(1): 2-7.

30. Ramaswamy S, Weinbauer GF. Endocrine control of spermatogenesis: Role of FSH and LH/testosterone. Spermatogenesis. 2014; 4: e996025. 